\title{
El encuentro en el juego: formulaciones sobre la reserva lúdica*
}

\author{
Sergio Fajn**
}

Recibido: 2 de octubre de 2019 • Aceptado: 10 de febrero de 2020

\section{Resumen}

Este artículo aborda el concepto de reserva lúdica, utilizado en el área de la psicogerontología y la teoría de la identidad flexible, con elaboraciones del campo del juego, del psicoanálisis y ciencias sociales. A partir de la reflexión, en este trabajo se consideran fenómenos en sujetos pertenecientes a diferentes generaciones, con especial atención a los acontecimientos que arman un posicionamiento saludable en el envejecimiento. El recurso elegido es una viñeta que narra el encuentro en el juego entre un nieto y su abuela, como sitio donde se plantean los ejes fundamentales que configuran las escenas lúdicas. La reserva lúdica se enciende al jugar y el mundo se mira desde el lugar que fuimos acumulando en nuestra reserva. En el encuentro lúdico y en el encuentro intergeneracional se estimula todo aquello que se almacenó para ser usado en el futuro. Para poder jugar necesitarán buscar posiciones plásticas o flexibles de modo que puedan acercarse a lo distinto, a lo diferente. El artificio de juego, en el escenario familiar, puede estructurarse como espacio de sostén subjetivo,

Artículo de reflexión, que retoma la discusión presentada en "Reserva lúdica: la identidad flexible en juego en el envejecimiento" (2019) y la investigación "Las prácticas comunitarias y su relación con los factores protectores del buen envejecer” (Zarebski y Marconi, 2013).

Citar como: Fajn, S. (2020). El encuentro en el juego: formulaciones sobre la reserva lúdica. Revista de Investigación Cuerpo, Cultura y Movimiento, 10(1), 19-38. DoI: https://doi. org/10.15332/2422474x/5959

"* Licenciado en Psicología, Universidad de Buenos Aires. Especialista en Psicogerontología, Universidad Maimónides. Miembro del equipo de investigación gerontológica, Universidad Maimónides, Buenos Aires, Argentina. Correo electrónico: piedralibre2001@gmail.com. orCID: https://orcid.org/0000-0001-7893-6683 
de oportunidad para la interrogación, revisión y rectificación de posiciones ya tomadas con respecto a la vida, al crecimiento y a los otros.

Palabras clave: identidad flexible, encuentro intergeneracional, juego, personas mayores. 


\section{The game as a place of encounter: Formulations on the ludic reserve}

Abstract

This article approaches the concept of ludic reserve, which is used in the field of psychogerontology and the theory of flexible identity, with elaborations in the field of the game, the psychoanalysis and the social sciences. Article of reflection. The approach considers phenomena in individuals belonging to different generations, drawing special attention to events that create a healthy positioning in the aging process. The chosen resource is a cartoon that shows the encounter that takes place in the game between a grandson and his grandmother, as the place where the fundamental axis that shape the ludic scenes are set out in all their splendor. The ludic reserve is triggered when playing, the world is observed from the place we have been accumulating in our reserve. In the ludic encounter and in the intergenerational encounter, everything that was stored to be used in the future is stimulated. In order to play, malleable or flexible positions are required, so as to be able to get closer to that which is different, distinct. The game device, within a family setting, can be structured as a space of subjective support, which gives the opportunity to question, revise and rectify positions already taken with respect to life, growth and the others.

Keywords: flexible identity, intergenerational, game elderly persons. 
Insistir demasiado en sí mismo es gastar sin sensatez la sustancia del mundo $y$ abusar de la luz y sus reflejos, del prorrateo abierto del mirar, del reparto de los colores y también del corazón de las tinieblas.

Es preciso insistir en otra parte, por ejemplo alli donde las lineas retroceden $y$ las manos se enguantan Si. Es preciso insistir en otra parte. Roberto JuARroz, Novena poesía vertical

\section{Introducción}

En este texto se aborda el concepto de reserva lúdica, que se utiliza en el área de la psicogerontología, articulada con los contenidos de la teoría de la identidad flexible y con otras nociones del campo del juego provenientes del psicoanálisis y de las ciencias sociales. En este artículo se indaga sobre cómo el dispositivo de juego, en el escenario familiar, puede estructurarse como espacio de sostén subjetivo, de oportunidad para la interrogación, la revisión y hasta la rectificación de posiciones ya tomadas frente a la vida, frente al crecimiento y frente a los otros. Es un lugar y una oportunidad también para que se desplieguen el deseo y la reconstrucción de los proyectos futuros.

Aquí se contribuye con algunos aportes para enriquecer una comprensión acerca de lo que le sucede a la persona respecto a su proceso de envejecimiento y cómo la posición subjetiva que adopte condicionará su enfrentamiento a las marcas sociales y a las marcas biológicas que lo atraviesan en este proceso (Zarebski, 2018).

La teoría de la identidad flexible y factores protectores para el envejecimiento, postulada por Graciela Zarebski (2019), nos posibilita comprender que las distintas calidades de envejecimiento a las que asistimos en estos tiempos corroboran que, a pesar del deterioro del organismo, el sujeto no necesariamente declinará a nivel emocional y que, aun en aquellos que sufren condiciones sociales adversas, su fortaleza emocional les permitirá seguir luchando por su vida y su lugar en el mundo. El ser humano no es solo efecto 
de su cultura y de su biología, de lo que le provoca su medio social y le ocasiona el deterioro de sus funciones, sino que, al mismo tiempo, es un sujeto proactivo, constructor de su cultura, de su cuerpo, de su historia y, por lo tanto, de su modo de envejecer.

Es de destacar la importancia de los vínculos tardíos, en este caso intergeneracionales, para reorientar la propia vida de la persona mayor que se encamina hacia un proyecto mortífero o tanático. En este sentido, se plantea el trabajo de elaboración del duelo a través da las práctica lúdicas y, sobre todo, la importancia del juego como método para explorar cualidades facilitadoras del despliegue de la subjetividad en el envejecimiento, la identidad y su flexibilidad. Esto favorece el desarrollo y la fluidez de los diversos factores protectores que permitirán llegar y mantenerse en un envejecimiento satisfactorio.

El concepto de reserva lúdica (Fajn, 2019) nace de la noción de reserva humana propuesto por Zarebski (2011). La reserva lúdica es un conjunto de recursos, herramientas, palabras, sonidos, acciones que porta el sujeto y deben actualizarse para poder ser usadas en el escenario de los juegos. Es lo que permite jugar aquí y ahora. En las personas mayores los conduce a su flexibilidad y a diversos factores protectores.

En la reserva lúdica anidan los recuerdos de los encuentros de juego realizados con los otros; está ahí lo singular, lo propio de lo que han sido "ellos", sus historias, gestos, risas. Es el material que se halla compartido en la memoria de la reserva de otros, al que se puede apelar para volver a recrearlo, pues ya se estuvo ahí.

En el encuentro en el juego con otras generaciones, se pone en actividad la reserva lúdica. Se le exige que sea plástica, flexible, para poder acercarse a lo distinto, a lo diferente, a lo que ya no es como era antes, exigencia del dispositivo de juego y de los sujetos para convertirse en jugadores. Asimismo, la reserva lúdica preserva al sujeto en la autonomía de su deseo. Solo jugará y desplegará sus escenarios y escenas si lo desea. No habrá juego obligado. Juego y obligación se oponen, se expulsan. El juego reserva y preserva el deseo.

La reserva lúdica posibilita al sujeto atravesar por aspectos centrales del envejecer y favorece la creación de escenarios artificiales y protegidos que permitan jugar con el armado de las continuidades y las discontinuidades en el transcurso vital, de modo que tiene contacto con aspectos centrales de su identidad. La reserva da los contornos, que delimitan y protegen, y que toman los rasgos de lo familiar, y construye lo familiar alejándolo de lo siniestro y 
amenazante; en últimas, la reserva ampara y aleja lo peligroso o terrorífico; habilita el armado de escenarios de juego que hacen sentir al sujeto en un lugar donde se está, pues en el juego uno es más uno mismo.

\section{En el origen estuvo el juego}

Finales de agosto. Han pasado tres meses desde que Chiche ha fallecido. Cora, su mujer, está viviendo en el más allá, en el tiempo que no proyectó, en el que no había futuro. Una vez, alcanzó a decir: “[...] Que ya no iba a valer la pena seguir si no estaba él, qué sentido iba a tener la vida”.

La internación de Chiche transcurrió como un mes de descubrimientos, un espacio intensivo para estar, verlo, hablarle, despedirlo. Quizás en ese periplo se desplegó la vuelta necesaria y definitiva del duelo y esto le posibilitó aceptar que se estaba yendo y que ella podría continuar y reconsiderar su decisión.

Cora, con sus 82 años, inaugura un nuevo tiempo, el que llega después de la despedida. Ahí se abre algo inédito, no calculado ni previsto. El futuro llegaba hasta que la vida de él se apagara. Chiche fue su amor, compañero, esposo y amigo de toda la vida. Permanecieron juntos durante 66 años, desde que ella tenía 15. Venían desde hace tiempo unidos, compartiendo caminos, sueños, utopías, nacimientos, encierros, latidos, pérdidas, conquistas. Cuando él enfermó, decidió sostenerlo y amarlo como siempre.

Emanuel, su nieto de 11 años, refunda el lazo con su abuela. La impulsa a renacer, la provoca, mira y convoca a asumir lo que viene: rehacerse. La madre de Emanuel prepara las condiciones, siembra el terreno y le pide que lo vaya a retirar a su colegio.

Cora acepta la invitación. Sale de su casa segura y va a buscarlo a la puerta de la escuela, como hacía antes de que su marido se enfermara y que el párkinson lo dejara cada vez más discapacitado. En ese momento, Cora se entregó plenamente y de manera exclusiva a Chiche, y dejó y se alejó de otros mundos. Decisión consciente y deliberada fue invertir casi toda su energía en cuidarlo.

Emanuel comienza ahora un trabajo de recuperar a su abuela. Va en búsqueda de los lugares que los han reunido alguna vez, los puntos de contactos únicos y exclusivos, solo de ellos. Anida ahí lo singular, lo propio de lo que 
han sido, sus historias, gestos, risas. La tarea que se propone Emanuel parte de la premisa de que hay una reserva compartida, que estas cosas han estado conservadas en la reserva lúdica que construyeron juntos. Esos instantes disfrutados con ella están guardados en esa memoria, él lo sabe y sabe que ella lo sabe. Su trabajo es darles vigencia, traerlos aquí y ahora, ponerlos en juego, jugando.

Al salir de la escuela estalla de alegría al ver a su abuela. Como siempre, flaquita, con un poco de panza, usando ropa sencilla y zapatos gastados. Lo espera con emoción. Se abrazan y se toman de las manos. Marchan hacia el colectivo 99, que va directo a la casa de Emanuel. En cuanto llegan, abre una bolsa repleta de comidas preparadas para él y para sus padres.

\section{Se ablandan}

Primera parada, la cocina. Ambos saben que eso los divierte. Se ponen un delantal y se disfrazan de cocineros. Planean hacer unos panqueques. Empieza a provocarla, la incita buscando recetas en la web y ella insiste con sus fórmulas de siempre: tanto de leche, un poco de harina y agua calculada a ojo. Cora lo aprendió así de su abuela. Luchan por imponer sus modos, pero finalmente pactan y empiezan con las mezclas. Enseguida, se va armando el clima, todo se riega de harina y azúcar, sus cuerpos se cubren y manchan, meten las manos en la masa. Entre ellos se ablandan y hallan buena temperatura. La cocina pasa a ser el lugar donde todo sucede, se ha transformado en una zona donde todo está permitido, todo se puede decir, todo se puede tocar. Se rozan, empujan y contagian. El olor los impregna y la ternura empieza a tejer el ambiente. No hay nada más en el mundo que ellos dos, no hay apuros ni urgencias.

Se empieza a formar un clima de juego. La magia se apodera del lugar. Ya no es la cocina; están sumergidos en otra dimensión, fueron a parar a ese sitio que lograban surcar años atrás, ya están ahí. Han tironeado y ella se ha dejado llevar a ese reino. Es como antes, pero a la vez no lo es. Logran reingresar al mundo del placer, la ilusión y el juego, pero no son los mismos.

Una y otra vez traen la figura del abuelo, recuerdos de él y su ausencia se hace presente. Hablan de escenas compartidas. Ríen, cuentan historias y anécdotas de lo que él hacía y decía. Evocan situaciones de cuando el abuelo jugaba con Emanuel y con los otros nietos. 
Están protegidos. El ambiente fabricado expulsa el sufrimiento y el dolor los aloja en un territorio de caricias. El juego los preserva. En tanto estén ahí saben que nada grave les va a suceder. Los une el amor. El espanto queda afuera. La posibilidad de la muerte, las enfermedades y las penas no ingresan. Pueden compartir los recuerdos de lo que ya no está, sin riesgos de ser tomados por el padecimiento.

Todo es conducido por el sendero del placer, ruta que sostiene el devenir lúdico. Es el armazón, la telaraña que ellos componen y el sitio donde se amparan. La telaraña flexible y sólida se estira, achica, balancea, pero no se rompe. En ese territorio, las palabras fluyen, las miradas abrazan, los permisos abren compuertas.

Es un tiempo fuera del tiempo, un hueco en la realidad que diseña un nuevo mundo, un rato de una nueva realidad habitada por la levedad, por lo efímero, por lo fugaz. Territorio dominado por la espontaneidad donde todo puede acudir a la cita (Fajn, 2017; 2019). Aunque el pasado viene hacia ellos, esto no es lo mismo que otras veces; no es idéntico. Reconocen que las cosas han cambiado, ambos han crecido. Ella está más sabia; él, atravesando la pubertad. Tiempo de encuentros con las transformaciones en el cuerpo y en la vida.

\section{Flotando}

Se autorizan a quedarse flotando en el olor de la manteca que se disuelve en la sartén, entonces, inician una riesgosa prueba de acrobacia y el panqueque vuela por el aire. El suspenso se adueña de la cocina y temen que vaya directo al piso, pero, por el contrario, en una pirueta da un salto mortal y vuelve a entrar justo y perfecto en la panquequera. Gritan de alegría, las carcajadas los inundan. Ambos lo hacen y lo logran. Ya están en condiciones de pasar a la siguiente prueba. Destapan el dulce de leche y luchan por apoderarse de la cuchara. Ella quiere fijar la cantidad para comer de panqueques y de dulce.

Cora ha dicho reiteradamente que en la tradición familiar el límite para comer son tres y con poquito dulce, si no, vaya a saber qué desgracia sucedería. Emanuel va por más y come sin parar rompiendo a pedazos la regla familiar. Va por el cuarto y aún no piensa parar. Los ojos le brillan de gusto y ella cede, entra en la picardía y también come cuatro, quizás por primera vez en su vida. 
Los invade la felicidad; han cruzado el umbral de lo permitido por los mitos familiares e ingresado al reino del puro placer. Están ahí acompañados, cómplices, seguros y triunfantes.

La gratificación le ganó a la desgracia. Van juntos recorriendo el nuevo andar.

\section{El futuro en juego}

Desde que la enfermedad de Chiche se agravó, los días de Cora cambiaron. Se instaló para ella el tope de que su vida llegaría hasta el momento en que su marido dejara de respirar, luego se acabaría también para ella. Este límite actuó como destino, ya que el futuro estuvo sellado, marcado por ese acontecimiento. Un techo autoimpuesto que resultó organizador de todo lo anterior, que le dio sentido a todo lo que hizo previamente. Las coordenadas por donde transitó fueron configuradas bajo la premisa de que hasta allí llegaría su vida. Esta idea de destino ha tenido un papel fundamental durante los últimos 5 o 6 años de Cora, casi todo lo que vendría estuvo signado por el fin. Es decir, al establecer y fijar un límite a su vida todo lo que ha hecho quedó atado a esta marca: el día de la muerte de su marido sería también su final. ¿Qué es lo que conmueve a Cora para que pueda romper ese techo una vez fallecido su marido y lanzarse hacia adelante para que aparezca nuevamente la perspectiva?

El futuro viene de la mano de su nieto menor, que la provoca, tironea y estimula a demostrar que hay algo más aquí. ¿Dónde se hace la operación de horadar el futuro, de agujerear el destino sellado y pasar al otro lado?, esa operación es facilitada también en el juego. En el encuentro en el juego se van autorizando juntos a ensayar como podría ser lo que viene. Se deja llevar por su nieto, así como años atrás ella lo llevaba a él, y confía en que nada serio le puede pasar, esto abre las compuertas para que se efectúen operaciones sobre el tiempo, sobre la imaginación, sobre los acuerdos establecidos con su marido acerca de que sucedería luego de que alguno de ellos falleciera. Trabajo de desarmar representaciones soldadas.

El dispositivo de juego habilita a Cora y a Emanuel a recorrer y experimentar en un ambiente de ficción, que podría acontecer también en la vida cotidiana, pero en el juego lo hacen existir como ensayo, sin riesgos. 
Hacen existir lo que vendrá o podría venir, hablan de lo que aún no está, él le hace saber de su deseo de hacer otras cosas con ella. Le hacen lugar a lo que estaba en retirada, a lo que ya no estaba entre ellos: las risas, las carcajadas. Pueden disfrutar sin tener que sufrir, componer proyectos, escenas y situaciones que no lo incluyen a Chiche, colaborando en la realización de un duelo saludable. Hay reencuentro con estados de ánimo, gustos, deseos, sueños y placeres.

Jugar se convierte así para ellos en una ocasión propicia que les posibilita que aparezcan los bienestares superando los malestares: curación de los malos humores, promovida en el hallazgo de lo gustoso percibido en el cuerpo, en el paladar, y también en el campo de lo imaginativo, en el puro placer de representación, placer inmaterial que llamamos imaginación radical. Nos dirá Castoriadis (1983) que la imaginación radical es la facultad que caracteriza a un humano. Es la capacidad intrínseca al ser humano de experimentar placer simplemente a través de la representación; la facultad de hacer surgir un flujo ilimitado de representaciones no sometidas a fines predeterminados.

Esta es la potencialidad creadora desprendida de las funciones, es afuncional y es lo que sostiene la capacidad sublimatoria en todo sujeto. Una vida vivida para el cumplimiento de las funciones es, según Castoriadis (1983), propia de un "viviente", no de un humano. Dice Zarebski (1999) que seguir manteniendo un "funcionamiento" normal en la vejez, es decir, darle continuidad a la tarea de hacerse humano hasta el último suspiro, va a depender de la riqueza del mundo afuncional del sujeto que envejece, de su capacidad recreadora. Esta riqueza le permitirá seguir sosteniendo su proyecto autónomo, seguir siendo permeable y lúcido respecto de sus deseos y actuar en consecuencia y, en tanto sujeto reflexivo, poder cuestionar el imaginario social de su época. Esta tarea la hace Cora.

Se conforma entre ellos dos un dispositivo artificial; es decir, arman una nueva realidad, que les da contorno y provee de seguridades para avanzar hacia lo imprevisto, lo no calculado. Van quebrando la realidad seria y montan una nueva realidad construida a su medida, a la medida de ellos. Es un dispositivo poroso y sensible, amable y cordial que toma vida, la vida que le dan sus jugadores.

En un momento, el dispositivo toma vida y Cora y Emanuel son sujetados, moldeados, intervenidos por lo que allí acontece. Es lo que han hecho existir, que los envuelve y atraviesa. Ese contorno los tornea, ese contexto es texto, los escribe y les deja marcas. Juegan y son jugados, se entregan, se dejan perder en 
eso que va haciéndose. Se van rehaciendo en eso que está surgiendo. Resurgen y se reaniman en lo que van produciendo.

Dice Marrone (2005) que estos sostenes son el contorno que constituye la prueba de la presencia del otro, la que rescata al yo del aislamiento y afinca en lo humano. El cruce de miradas, sonrisas y complicidades diseña y consolida una red que sostiene, que tiene al otro, que da volumen y consistencia para el armado y existencia de una malla invisible que propicia el estallido de risas, carcajadas, bromas, buenos humores (Fajn, 2019).

Mientras Cora y Emanuel van cocinando, se arma la burbuja de acuerdos para que este, el lugar de juegos, sea un espacio protegido, la magia acontezca y brote de repente el humor, la alegría, la diversión, la mueca blanda. Surge lo irracional, lo no pensado, las emociones, las sensaciones libres de ataduras; la rotura con el orden establecido (Fajn, 2018; 2019).

La imaginación domina la escena. Los cocineros se van montando sobre las creencias, sobre el acuerdo de creencias de que son cocineros y todo puede suceder ahí libremente hasta que se sienta que esto ya es otra cosa, otro mundo; breve, eterno, ingenuo, inmortal, fértil, inmaterial, infantil, atemporal, seguro, simple, fantástico (Fajn, 2001; 2019). Es una trama de construcción compleja que necesita que los participantes de este ritual se arrojen y se despojen de sus seguridades y se tiren al gobierno del caos.

Es necesario entonces interrumpir el orden de la vida ordinaria, destruirlo temporalmente para fundar, en el vacío que queda en su lugar, el orden lúdico (Scheines, 1998). Cualquiera puede ganarse si se deja perderse (Fajn, 2019).

En el juego, durante el juego, ambos van recuperando lo que venían haciendo gustosamente antes de que se intensificara la enfermedad de Chiche y ella se dedicara a él.

La enfermedad aparece aquí bajo el formato de la detención del deseo y a la imposibilidad para seguir proyectando y a continuar viviendo más allá de Chiche. Por el contrario, lo saludable se expresa como apuesta a ocupar otro lugar, el que vendrá. La de la operación de autorización a verse disfrutando sin Chiche, de seguir viviendo sin él al lado, de la mano; a construir nuevas imágenes de sí misma, rehacerse sostenida entre otros, por su nieto.

Juntos, abuela y nieto, se amparan y potencian al reencontrarse en aquel sitio conocido y seguro de otros tiempos y desde esa plataforma despegan hacia lo nuevo, ensayan nuevas formas; transgreden los límites impuestos por los mandatos familiares que encorsetan y estallan en el contacto con el placer, 
el gusto y el disfrute. Tantean al hacerle lugar a lo perdido, a los recuerdos del abuelo y el marido. Este se hace presente sin que les provoque angustia o sufrimiento; por el contrario, hay risas, ironías y reencuentros con él. Es bienvenido en el juego, le abren la puerta, viene para ser exorcizado, hay vapores, olores y sabores que lo envuelven. Lo doloroso queda afuera de la escena, la angustia no ingresa. Se puede hablar de él y jugar con su recuerdo: instancia de duelo saludable para ambos. Se lo puede tocar, nombrar, bromear. Se lo desdramatiza (Pavlovsky, 1999).

Chiche fue participe de cuanto juego se armaba en la casa y, aun en tiempos de enfermedad, supo sumarse a infinidad de iniciativas. Traerlo hoy es invitarlo a un espacio conocido y gustoso en el que seguramente estaría cómodo.

Allouch (1994) dice que cada uno se encuentra habitado por sus muertos. Sostiene que el duelo no es separarse del muerto, sino cambiar la relación que tenemos con él y agrega que " [...] la posición de cada uno con respecto a alguno(s) de sus muertos está funcionando permanentemente en las determinaciones más cruciales de su vida, en ciertos trazos en apariencia de lo más anodinos [...]" (p. 55). Cuando en un juego efectivamente se juega, inevitablemente se produce algo nuevo, se crea, y no hay creación posible sin el riesgo del pasaje por la zona de la muerte, de lo muerto de cada uno. De una manera diferente de manipular, tratar o entenderse con lo muerto, surge la creación, es decir, lo vital (O’Donnell y Gili, 1978).

\section{En reserva}

El tironeo de Emanuel apunta a recrear y a reencontrarse con lo que alguna vez estuvo. Sabe que eso jugado quedó guardado en algún lugar, está en reserva. Ahí estuvo preservada su abuela todos estos años. ¿Pero cómo hacer para recuperarla? Provocándola, incitándola a pasar otra vez por esos lugares que juntos surcaron. Le insiste una y otra vez que tienen que cocinar juntos, le dice qué es lo que le gustaría. Así logró encenderla; descubrió la apertura, el agujero por el cual entrar en ella y hallar lo que estaba bien guardado. No estaba destruido, estaba en reserva, a la espera de ser activado, puesto en circulación.

Se arma así el escenario y la escena de juegos. El escenario naturalmente es la cocina. Se necesitan de ingredientes, condimentos, sal, azúcar, harina, aceite y de ollas, sartenes y cucharas. Un delantal para cada uno que les permite ser 
y estar distintos, disfrazarse y convertirse en personajes, los cocineros. Uno de los modos de entrar en clima es cuando Emanuel la provoca, punza sobre sus aspectos más rígidos, sus callos. La provoca con sus palabras, buscando otras recetas, llenándolas de harina. Sabe que esto la saca de su forma de ser habitual, su estilo de ser tranquila, de la conocida abuela. Apelar a la provocación la transforma en jugadora, la anima a ser y hacer cosas no habituales. La mueve y la lleva a ser flexible, condición necesaria e imprescindible para que acontezca el juego. La despoja una y otra vez de sus durezas. La acompaña a parirse nuevamente, a salirse de lo ya establecido y poder sumergirse en lo desconocido, en lo no calculado, en lo no previsto. Va segura, caminando y entrando en la zona de juego de la mano de su nieto. No se van a lastimar, él la cuida y ella lo cuida. El juego los cuida.

Como si frotaran la lámpara de Aladino, el clima que van creando trae y extrae lo que estaba guardado en la reserva lúdica, aquellos recursos, modos, estilos, voces que fueron territorio de disfrute en otros tiempos. Eso viene al hoy, se hace presente, les resulta conocido. Se reconocen. Ambos se sitúan en el juego, están en juego. Se despliega la alegría. Se mueven, hablan y vinculan de modo diferente a la vida seria, a la vida de no juego. Todo esto estaba alojado en la reserva lúdica de cada uno de ellos.

Ahora, ninguno de ellos son los mismos, el tiempo ha pasado, son diferentes, han mutado, han crecido, el tiempo les ha tallado el rostro y los cuerpos. Para que la magia del juego permanezca, será necesario rectificar las formas, las velocidades, los ritmos, los códigos; acomodarse a lo que son ahora. Será necesario tener flexibilidad en el modo de estar, de ser, de encontrase para que el disfrute los tome. Esta revisión y rectificación la van haciendo durante el mismo juego. Jugando pujan por encontrar lo mejor de ellos.

Al terminar de cocinar los jugadores ya no son los mismos. Viajaron por un itinerario en donde se han soltado de la tierra firme, para que luego, una vez finalizado el juego, logren regresar enriquecidos. Juntos fueron surcando el devenir, el trayecto, amparados por el deseo de disfrutar de modo compartido, de jugar, de parar el mundo, de estar y vivir en otro mundo, distinto, mejor. Regresan a la realidad de no juego, mejorados, más sanos, recompuestos, regenerados, alegres, distendidos, recreados (Fajn, 2019).

La apuesta implica la convicción de que no se gana sin pérdida. Cora y Emanuel van en esa búsqueda, ese es el viaje, y ambos se ofrecen para que esto aparezca. El fenómeno, la magia, viene a la fiesta. Cuando cada uno se 
va entregando, el cambio aparece. Todo se va configurando. Van armando y creando el clima de alegría en la cocina. Lo que no estaba viene y se hace presente. Lo duro se va, lo blando llega. Lo impermeable se agujerea y se llena de poros, de perforaciones que abren las compuertas para que algo vibre, suene, estalle y surjan nuevas formas, palabras e imágenes (Fajn, 2019).

\section{El encuentro de juego como dispositivo para vivir mejor}

Para Cora, el pacto con la detención del deseo hizo que este quedara capturado y solamente destinado al tiempo en que su marido viviera. Encuentra ahí, en el otro, la salida, el tejido para habitar un lugar donde vivir, para amarrar y relanzar su perspectiva en la vida.

El juego aparece como una instancia de ayuda para Cora y como lugar de intervención de su nieto. Ahí pueden hacer y rehacerse, operar sobre lo que insiste. Esta plataforma permite ponerle un dique a lo que insiste demasiado y puede convertirse en un exceso, dice Alterman (1991), que se trata de tramitar un exceso por la vía del juego.

$\mathrm{El}$ artificio del juego al componer un contorno es que puede apaciguar frente al avance de la desmesura, de lo insoportable, de lo ominoso que se convierte en terrorífico (Marrone, 2005). Es un contorno que preserva de ser gozado. Cuando el contorno se borronea, si se borra el contorno familiar, aparece lo ominoso y se puede ingresar en la zona de las perturbaciones del narcisismo sin suficiente protección respecto del mundo y de los otros (Freud, 1919). Por el contrario, la figura-contorno ofrece el soporte imaginario necesario para la estabilidad del narcisismo (Marrone, 2005).

La flexibilidad constituye el principal atributo de un narcisismo normal (Freud, 1914; Bleichmar, 1981; Salvarezza, 1996). El grado de flexibilidad o de rigidez llevará a la aceptación o no de los cambios y las transformaciones que implica el envejecimiento para la propia identidad, y se pondrá en juego respecto a puntos de vista, hábitos y rutinas, pérdidas, roles y vínculos. De tal modo, las vicisitudes de la posición frente a los límites irán acompañando al sujeto en todos los planos de su transcurrir vital, incluido el gran límite: la muerte (Zarebski, 2015).

El artificio del juego puede proveer al sujeto estos recursos para la estabilidad del narcisismo. (Fajn, 2019). La invención artificial da bordes en 
los cuerpos, en los vínculos, en las vivencias y en las percepciones subjetivas. En la medida que aparecen bordes, se reducen los riesgos de desbordes emocionales; hay mayor y mejor autocuidado y cuidados de los otros, y protección contra las actuaciones que amenazan la estabilidad del narcisismo (Fajn, 2019).

Es posible que para Cora el proceso de insistir en otra parte habilitando un lugar a su deseo más allá de Chiche haya sido una construcción que implicó desarmar lo que estaba escrito para ella. El destino seguro estableció un pacto de amarre con su marido, uno con el otro, en un gesto de amor indestructible. Pero ahora él ya no está más y ella se encuentra con el deseo de los otros, hijos, nietos, seres queridos. Esto agrieta y la conmueve, se entrelaza y emerge nuevamente su deseo que empieza a ligarse con otros objetos amorosos.

Desprenderse y renunciar al espacio seguro que tenía armado junto a Chiche implica una apelación a la configuración de su identidad. ¿Es posible para Cora rearmarse sin la presencia de Chiche?, ¿al perderse Chiche se tiene también que perder ella?

El gran desafío que nos plantea el envejecimiento en el plano personal es el modo en que nos posicionamos frente a los límites y transformaciones que el curso vital nos va poniendo en evidencia, a través de cambios y pérdidas, con mayor o menor grado de gradualidad y previsibilidad. En el curso vital se va produciendo la pérdida o transformación de nuestros referentes identificatorios, es decir, los pilares de nuestra identidad. Una pregunta nodal, a fin de entender las diferencias subjetivas frente a este proceso, es: ¿Eran "meros" referentes de nuestra identidad? ¿O representaban toda nuestra identidad? ¿Era una versión de nosotros aquello perdido o transformado o constituía todo nuestro relato? Estas preguntas aluden al modo de aferrarnos a esos pilares de nuestra identidad, es decir, la permeabilidad y fluidez interna y externa del entretejido dinámico de la red que nos constituye, por tanto, su flexibilidad o, por el contrario, su rigidez (Zarebski, 2019).

Su nieto, el más pequeño, representa una generación que le exige a Cora estirarse, salirse de lo conocido y de lo fijado. Emanuel le hace saber de su deseo de necesitarla, de que le hace falta, de que la estaba esperando para retomar los tiempos de felicidad compartidos. Y que no está dispuesto a perderla otra vez. Comprende que ella estuvo dedicada casi exclusivamente a atender al abuelo, pero ahora la quiere recuperar. La mueve, la conmueve en eso que ya tenía definido. Apela al terremoto, a moverle cielo y tierra, a sacudirla, 
a rehacerla con el material de lo que fue y le falta por hacer con ella. La estrategia, el laboratorio donde va a ensayar su experimento de reconstrucción y recreación de la abuela es jugando en la cocina. Allí brotará y emergerá lo que alguna vez estuvo. Habrá que agitar y revolver hasta que la nueva mezcla dé por resultado una nueva abuela que contenga a la vieja abuela, una nueva mujer que contenga a la anterior mujer, un encuentro entre el viejo nieto y el nuevo nieto, identidad flexible de ella, identidad flexible de él.

Cuando juegan aparecen historias que hablan del pasado. Ella trae, él trae, ambos cuentan anécdotas. En ese instante hay una apelación a la porosidad, una invitación a que el material que circula en las palabras y en las acciones tome vigencia y sentido. Esto demanda un trabajo interno de los dos, posición plástica de Cora para abrirse y dar acogida a lo que trae su nieto. También es deseo de Emanuel de identificar, conocer y reconocer lo que presenta su abuela. Es una invitación a impregnarse del otro, a dejarse habitar por el otro.

Dice Zarebski (2017) que las personas que desarrollan factores protectores estarían en mejores condiciones de continuar transmitiendo y recibiendo estímulos en forma bidireccional, creadora y transformadora. Esto supone seguir como sujeto activo en la búsqueda de los aspectos que le unen a su contexto encontrando el sentido de la vida, la correspondencia entre su mundo interior y el entorno.

Los factores protectores que arman un envejecimiento saludable están presentes en Cora, quien se va dando oportunidades para revisar sus posiciones frente al curso de la vida, se permite interrogarse, revisarse y rectificar los senderos por donde ha recorrido y por donde va a transitar. Ha construido una red familiar que contiene y sostiene, haciendo lugar al juego y a la broma como parte de la vida. Hoy nuevamente, frente a la adversidad, los diferentes factores que componen la trama se hacen presentes para dar respuesta y protegerla. Emanuel es parte activa de este proceso de movilización y, a su vez, arma también sus propias imágenes de cómo es envejecer, convive con un modelo. Ha visto envejecer a su abuelo y compartió con él sus modos, estilos de afrontamiento y hoy sigue encontrando otras versiones junto a su abuela. 


\section{Resultados y discusión: lo jugado queda inscrito}

Al jugar se actualizan nuestras historias de juego, de haber jugado. Lo jugado queda tatuado en el cuerpo, en algún lugar del cuerpo. Solo hay que volver a jugar, a pasar por el juego para que se reactiven, se reaviven las inscripciones y vengan al presente.

Es necesario convocar el pasado para que se haga presente. Al jugar se va guardando en una reserva junto a la reserva cultural, cognitiva, vincular, emocional, espiritual, cerebral, corporal — como parte de la Reserva Humana propuestas por Zarebski-, pero con la singularidad que se inscriben como recuerdos en clave de juego. Habrá que ver cómo fueron significados en su momento, ya que ingresarán a ese mundo, a ese registro, si tuvieron el sentido de juego, sino serán otras cosas. Hay una y mil oportunidades de reescribir las vivencias y transformarlas en experiencias. Las vivencias son las cosas sucedidas que al pensarlas y darles valoración pueden pasar al campo de la experiencia y se plasmen como juego.

Cora relata sus momentos de aprender a andar en bicicleta. Le cuenta a Emanuel que se convirtió en recuerdo imborrable a partir de que logró mantenerse en equilibrio sobre las dos ruedas, sin ser sostenida por su padre. El universo del juego se abrió en ese momento cuando sintió que dominaba el mundo, acto, para ella, fundante de la independencia y la autonomía, del disfrute de la libertad. Ubicado en un lugar inaugural y esencial de su reserva lúdica. Una y otra vez acude a estos episodios para referirse a sus grandes instantes de juegos.

La reserva lúdica se enciende al jugar, el mundo se mira, siente, percibe y piensa desde ahí, desde el lugar que fuimos acumulando en nuestra reserva. En el encuentro con otros, también en el encuentro intergeneracional se tironea de esto que quedó en guarda, en custodia para ser usado en el futuro. Los jugadores buscarán posiciones plásticas, flexibles para poder acercarse a lo distinto, a lo diferente.

Ya no es lo mismo que en las escenas vividas anteriormente, hace un año, hace cinco o 70 años. Hay que actualizarse, actualizar la reserva lúdica para que permita jugar aquí y ahora. Hacer de esta un sitio de la memoria, un conjunto de recursos, herramientas, palabras, sonidos, acciones que deben poder ser usadas en el escenario actual de juegos, si no, no se puede jugar. Jugar con el cuerpo que se tiene hoy, con sus posibilidades y sus limitaciones, 
jugar con los vínculos, con la agilidad mental, con la capacidad de expresión, de comunicación. Con todo lo que porta el sujeto. Se juega en serio o no se juega. Una reserva lúdica rígida no facilita estar y entrar en situación de juego. No permite jugar. No es posible acomodar la escena actual de juegos a lo que fue, es imprescindible poner toda la flexibilidad en juego para entrar en sintonía con lo que ahora llama y convoca (Fajn, 2015; 2019).

\section{Conclusiones}

El artificio de juego presenta cualidades facilitadoras para propiciar el despliegue del eje central de la subjetividad en juego en el envejecimiento, la identidad y su flexibilidad. De esta manera, se favorece el desarrollo y la fluidez de los diversos factores protectores que permitirán arribar y sostener un envejecimiento satisfactorio.

Asimismo, jugar preserva al sujeto en la autonomía de su deseo. Solo jugará y desplegará sus escenarios y escenas si lo desea. El juego es reserva y preservación del deseo. Jugar posibilita seguir ensanchando el mundo psíquico con estímulos, pensamientos, afectos y vínculos, con un lugar privilegiado en tanto y en cuanto los sujetos estén dispuestos, sin que la edad sea un límite.

$\mathrm{El}$ juego es un espacio poroso que favorece estar disponible para verse, y rehacerse, mirar las huellas transitadas, juntarse con el placer y el amor sabiendo que se está protegido del sufrimiento y de la presencia de lo siniestro; un escenario fértil para reconstruir el futuro dinamitando los prejuicios, mitos $\mathrm{y}$ valores que detienen el camino del deseo.

En este escrito recorrimos la noción de reserva lúdica ligándola con los contenidos de la teoría de la identidad flexible e intentamos dar cuenta de cómo el dispositivo de juego, en el escenario familiar, puede estructurarse como espacio de sostén subjetivo, de oportunidad para la interrogación, la revisión y hasta la rectificación de posiciones ya tomadas frente a la vida, frente al crecimiento y frente a los otros. Constituye un lugar y una oportunidad también para que se desplieguen el deseo y la reconstrucción de los proyectos futuros. 


\section{Referencias}

Alterman, R. (1991). De monstruos, pesadillas y juego. En A. Ariel y D. Laznik (comps.), La responsabilidad del analista. Buenos Aires: Editorial Estilos.

Allouch, J. (1994). Freud, y después Lacan. México: Edelp.

Bleichmar, H. (1981). El narcisismo. Estudio sobre la enunciación y la gramática inconsciente. Buenos Aires: Ediciones Nueva Visión.

Castoriadis, C. (1983). La institución imaginaria de la sociedad. Buenos Aires: Tusquets.

Fajn, S. (2001). Jugar no es jugarse la vida. Consideraciones sobre el duelo y el juego en el envejecimiento normal. En G. Zarebski y R. Knopoff, (comps.), Viejos nuevos, nuevos viejos. http://psicogerontologia.maimonides.edu/wp-content/ uploads/2017/12/Libro-Viejos_Nuevos-Nuevos_Viejos.pdf

Fajn, S. (2013). Las prácticas comunitarias y su relación con los factores protectores del buen envejecer. En: Zarebski, G. y A. Marconiv (comp.), Inventario de factores psíquicos protectores en el envejecimiento (FAPPREN). Editorial Académica Española.

Fajn, S. (comp.). (2017). Jugar en la primera infancia. Proyectos institucionales en contextos diversos. Novedades Educativas.

Fajn, S. (2019). Reserva lúdica: la identidad flexible en juego en el envejecimiento. En G. Zarebski, (ed.), La identidad flexible como factor protector en el curso de la vida (pp. 141-179). Buenos Aires: Editorial Universidad Maimónides.

Fajn, S., Campano, P. y Rozengardt, A. (2015). Recuperación de pautas de crianza, comunidad diaguita de Amaicha del Valle. Tucumán: Ministerio de Desarrollo Social de Nación, COCEDIC, Universidad Nacional de General Sarmiento.

Freud, S. (1992). Duelo y melancolía. Obras completas (López Ballesteros, trad.). Madrid: Biblioteca Nueva. (Original publicado en 1917).

Freud, S. (1919). Lo ominoso. Obras completas (López Ballesteros, trad.). Madrid: Editorial Biblioteca Nueva.

Marrone, C. (2005). El Juego, una deuda del psicoanálisis. Buenos Aires: Editorial Lazos. .

O’Donnell, P. y Gili, E. (1978). El juego. Técnicas lúdicas en psicoterapia grupal de adultos. Barcelona: Gedisa.

Pavlovsky, E. (1999). Espacios y creatividad. Buenos Aires: Editorial Búsqueda.

Salvarezza, L. (1996). Psicogeriatría. Teoría y clínica. Buenos Aires: Editorial Paidos. 
Scheines, G. (1998). Juegos inocentes, juegos terribles. Buenos Aire: Editorial Eudeba.

Zarebski, G. (1999). Una vejez normal. En Hacia un buen envejecer (pp. 25-48). Buenos Aires: Emecé.

Zarebski, G. (2011). El futuro se construye hoy. La reserva humana, un pasaporte hacia un buen envejecimiento. Buenos Aires: Paidós.

Zarebski, G. (2015). Factores Protectores para el envejecimiento. En A. Marconi (comp.), Narcisismo, resiliencia y factores protectores den el envejecimiento. Nuevos aportes al campo de la intervención e investigación en psicogerontología (pp. 31-57). Buenos Aires: Gerontólogos Argentinos.

Zarebski, G. (2019). Teoría de la identidad flexible y factores protectores para el envejecimiento. En La identidad flexible como factor protector en el curso de la vida (pp. 11-42). Buenos Aires: Editorial Universidad Maimónides 